\title{
Critical limb ischemia: current challenges and future prospects
}

This article was published in the following Dove Press journal: Vascular Health and Risk Management

\author{
Luigi Uccioli' \\ Marco Meloni' \\ Valentina Izzo' \\ Laura Giurato' \\ Stefano Merolla ${ }^{2}$ \\ Roberto Gandini² \\ 'Department of Systems Medicine, \\ 2Department of Interventional \\ Radiology, Università di Tor Vergata \\ Roma, Rome, Italy
}

\begin{abstract}
Critical limb ischemia (CLI) is considered the most severe pattern of peripheral artery disease. It is defined by the presence of chronic ischemic rest pain, ulceration or gangrene attributable to the occlusion of peripheral arterial vessels. It is associated with a high risk of major amputation, cardiovascular events and death. In this review, we presented a complete overview about physiopathology, diagnosis and holistic management of CLI. Revascularization is the first-line treatment, but several challenging cases are not treatable by conventional techniques. Unconventional techniques for the treatment of complex below-the-knee arterial disease are described. Furthermore, the state-of-the-art on gene and cell therapy for the treatment of no-option patients is reported.
\end{abstract}

Keywords: peripheral arterial disease, critical limb ischemia, medical therapy, revascularization, cell therapy

\section{Introduction}

Critical limb ischemia (CLI) may be considered the most severe pattern of peripheral artery disease (PAD), being associated with a high risk of major amputation, cardiovascular events and death. ${ }^{1}$ A mortality rate of $20 \%$ within 6 months after the diagnosis and $50 \%$ at 5 years has been reported. ${ }^{2,3}$ This excessive mortality may be related to the systemic cardiovascular diseases, including coronary artery disease and cerebrovascular arterial disease. ${ }^{4,5}$ Furthermore, CLI is associated with peripheral complications such as ulceration, gangrene, infection and a high risk of lower limb amputation estimated in $10 \%-40 \%$ of patients at 6 months, especially in non-treatable patients. ${ }^{6,7}$

\section{Definition}

According to the Inter-Society Consensus for the Management of Peripheral Arterial Disease (TASC II), CLI is defined by the presence of chronic ischemic rest pain, ulceration or gangrene attributable to arterial occlusive disease. ${ }^{7}$ Usually, the impairment of peripheral perfusion is a long chronic process that occurs along months or years in relation to age, predisposing factors and cardiovascular risk factors such as smoke, diabetes, hypertension, dyslipidemia, chronic kidney disease, hypercoagulable states and hyperhomocysteinemia. ${ }^{8}$

The diagnosis of CLI is defined by clinical findings associated with objective peripheral examination such as ankle-brachial index (ABI), toe systolic pressure and transcutaneous oxygen pressure $\left(\mathrm{TcPO}_{2}\right)$. CLI is considered in case of ischemic rest pain with ankle pressure $<50 \mathrm{mmHg}$ or a toe pressure $<30 \mathrm{mmHg}$ and in patients affected by
Department of System Medicine, Università di Tor Vergata Roma, Viale Oxford 81, 00133 Rome, Italy

Tel +3934837I 0745

Email luccioli@yahoo.com 
foot ulcers or gangrene by an ankle pressure $<70 \mathrm{mmHg}$, a toe systolic pressure $<50 \mathrm{mmHg}$ or $\mathrm{TcPO}_{2}<30 \mathrm{mmHg}^{7}$ Among CLI subjects, a subgroup of asymptomatic patients should be considered. They usually are sedentary or diabetic patients with peripheral neuropathy with reduced pain perception. In these patients, CLI is defined in case of ulceration or nonhealing ulcers in the presence of arterial occlusive disease.

\section{Pathophysiology}

CLI is usually the result of multi-segmental PAD with impaired blood flow in peripheral tissues. In some cases, the simultaneous presence of impaired cardiac output may worse the peripheral perfusion in CLI patients. The reduced oxygenation and nutrition of peripheral tissues may cause claudication or rest pain, even if this typical symptom of PAD may be reduced or absent in diabetic patients with neuropathy. Furthermore, diabetic CLI patients show usually distal arterial lesions characterized by the involvement of the vessel below the knee (BTK), and often the first signs of PAD are ulceration, necrosis or gangrene.

\section{Diagnosis of PAD and CLI}

The detection of PAD/CLI is characterized by different steps. The holistic approach requires the identification of cardiovascular risk factors and the evaluation of peripheral pulses (femoral, popliteal, dorsalis pedis and posterior tibial artery) even if their presence cannot exclude completely a potential condition of ischemia. ${ }^{9}$ The diagnosis of PAD is usually the result of clinical evaluation associated with one or more instrumental examinations. Among the first-level examinations, we find ABI, TBI, TcPO 2 and ultrasound (US) color duplex. The second-level examinations included are magnetic resonance imaging (MRI) and computed tomography (CT). ABI defines a condition of reduced peripheral blood flow if $<0.9$. A value $<0.4$ identifies a severe ischemia. ABI $>1.3$ may be related to peripheral calcification and PAD cannot be excluded. Normal values are between 0.9 and $1.3 .^{10,11}$ TBI $<0.50$ associated with abovementioned clinical findings identifies a condition of CLI. ${ }^{12} \mathrm{TcPO}_{2}$ is usually used to identify the chance of healing in diabetic patients with foot ulceration (FU). Furthermore, revascularization is often indicated in patients with foot ulcers and $\mathrm{TcPO}_{2}<30 \mathrm{mmHg}$ to allow wound healing (Box 1). ${ }^{13}$

US color duplex is a sensitive and specific examination that allows to obtain several data about peripheral flow even if it is related to personal skills and patient's compliance determined by the operator dependence and the patient collaboration. ${ }^{14,15} \mathrm{MRI}$ and $\mathrm{CT}$ are the gold-standard to detect
Box I Definition of CLI

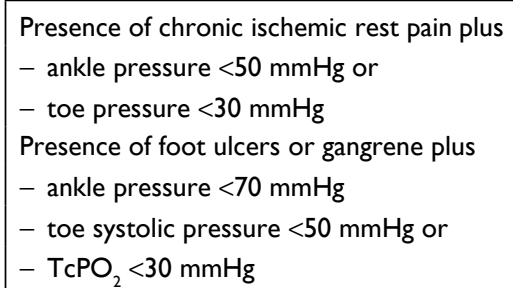

Abbreviations: $\mathrm{CLI}$, critical limb ischemia; $\mathrm{TcPO}_{2}$, transcutaneous oxygen pressure.

the arterial lesions. They provide an accurate description of stenosis or obstructions and could help the vascular surgeons or the interventional radiologist performing the revascularization. ${ }^{16}$ MRI is not indicated in patients with pacemaker, sutures and metal implants and claustrophobic patients. Furthermore, it cannot be performed in patients with glomerular filtration rate $<30 \mathrm{~mL} / \mathrm{min}$ due to the high risk of nephrogenic systemic fibrosis. ${ }^{17-19}$ In addition, CT allows a clear evaluation of peripheral arterial district. Its limitation may be related to the use of iodinated contrast organ and increased risk of contrast-induced nephropathy in patients with severe chronic kidney disease ${ }^{20}$ In high-risk patients with impaired renal function, some data support the use of carbon dioxide $\left(\mathrm{CO}_{2}\right)$ as an alternative supplemental contrast agent that can be applied safely preventing kidney dysfunction. ${ }^{21}$

\section{Holistic management of CLI patients}

The goal of CLI treatment is to relieve pain, allow wound healing, improve patient's function, prevent limb amputation and reduce mortality. Lower limb revascularization is the first-line treatment in CLI patients that can tolerate this procedure. In few cases, CLI patients with multiple comorbidities or low chance of successful revascularization may require a primary amputation. A simultaneous medical intervention is required for pain management, control of cardiovascular risk factors and optimization of glycemic control.

\section{Medical treatment Pain}

Pain management is essential to improve quality of life and function. Commonly, in the majority of cases, adequate peripheral revascularization relieves peripheral pain. In no option-CLI patients, identified as subjects not treatable by revascularization, medical therapy is mandatory. Paracetamol and nonsteroidal anti-inflammatory drugs are usually the firstline treatment even if opioids are often required. Usually, a 
regular administration of analgesic therapy is more effective than that on demand. Owing to the presence of peripheral neuropathy, in some cases, pain may be neuropathic. A careful differential diagnosis should be performed because neuropathic pain may require a different therapeutic approach.

\section{Smoking}

Smoking cessation is strongly required to reduce the worsening of PAD and the risk of major amputation and any cardiovascular events. Furthermore, smoke increases the risk of revascularization failure. ${ }^{22}$ Furthermore, smoking cessation reduces mortality and improves amputation-free survival in patients in comparison with those who continue smoking. ${ }^{23}$

\section{Dyslipidemia}

Total cholesterol, low-density lipoprotein cholesterol (LDL-C), triglycerides and lipoprotein(s) are risk factors for development and progression of PAD. ${ }^{24}$ The use of statins in PAD patients is recommended. It is well documented that low levels of LDL-C reduce cardiovascular events (myocardial infarction, cerebrovascular events), and the goal in all patients with PAD is LDL-C $<70 \mathrm{mg} / \mathrm{dL}^{25,26}$

\section{Hypertension}

Guidelines suggest a close control of blood pressure with values $<140 / 90 \mathrm{mmHg}$ in all patients and $<130 / 80 \mathrm{mmHg}$ in diabetic patients or patients with proteinuria. ${ }^{27}$ All drugs that are effective in lowering blood pressure can be used: thiazide diuretics, angiotensin-converting enzymes (ACEs), angiotensin receptor blockers (ARBs), calcium channel blockers $(\mathrm{CCBs})$ and beta-adrenergic blockers. In diabetic patients, $\mathrm{ACE}$ and $\mathrm{ARB}$ are considered as the first-line treatment.

\section{Diabetes}

Diabetes is recognized as a strong risk factor of PAD. A close control of glycemia should be considered to reduce the progression of micro- and macrovascular complications even if PAD is usually related to different cardiovascular risk factors. ${ }^{28,29}$

Diabetes increases the risk of PAD approximately threeto fourfold and the risk of claudication to twofold. Most patients with diabetes have other cardiovascular risk factors (smoking, hypertension and dyslipidemia) that contribute to the development of PAD. Diabetes is also associated with peripheral neuropathy and decreased resistance to infection, which leads to an increased risk of foot ulcers and foot infections. Furthermore, there is a common thought that impaired glycemic control may increase the risk of nonhealing of diabetic foot ulcers even if there are no studies that evaluated the impact of $\mathrm{HbA} 1 \mathrm{c}$ on the outcomes of diabetic foot ulcers. However, HbA1c is considered as a predictor of major amputation, ${ }^{30,31}$ and hyperglycemia is an independent risk factor for mortality in hospital patients with diabetic foot. ${ }^{32} \mathrm{HbA} 1 \mathrm{c}<7.0 \%$ is the goal to reduce the risk of macrovascular complication and progression of PAD. ${ }^{30}$

\section{Antiplatelet therapy}

Aspirin/acetylsalicylic acid (ASA) or clopidogrel is indicated for secondary prevention in patients with PAD and/ or other cardiovascular diseases. Low dose of aspirin/ASA (75-160 mg) is effective and safe during related complications such as gastrointestinal bleeding. ${ }^{33}$ In diabetic patients who undergo lower limb revascularization, dual antiplatelet therapy (ASA+clopidogrel or ticlopidine) is recommended for at least 1 month after endovascular procedure; after 1 month, ASA or clopidogrel should be lifelong continued. ${ }^{34}$

\section{Treatment of CLI}

Revascularization is the first-line treatment for CLI. Revascularization may be surgical through bypass or endovascular technique. There is an open debate whether open surgery is preferable or not to angioplasty. Nowadays, the decision is related to many factors: anatomical lesions, distribution of arterial disease, patient's health status, comorbidities, presence of foot ulcer and foot infection and local expertise.

The Bypass versus Angioplasty in Severe Ischemia of the Leg (BASIL) study was a multicenter, randomized controlled trial that compared bypass surgery first vs angioplasty first in patients presenting with CLI due to infrainguinal disease. ${ }^{35}$ In the middle term, the rates of amputation-free survival, allcause mortality and health-related QOL were similar in both groups, while morbidity and hospital costs were higher in the surgery group in comparison with the endovascular group. In relation to long-term outcomes, the surgical patients who achieved limb salvage $>2$ years reported a longer survival than the angioplasty patients.

Two meta-analysis reviewed infrapopliteal angioplasty in CLI patients in comparison to popliteal-distal vein bypass grafts in a homogeneous cohort of patients. The rate of limb salvage was similar comparing open surgery and endovascular approach. $^{36,37}$ Therefore, the authors support percutaneous transluminal angioplasty (PTA) as a useful option to treat CLI.

\section{CLI in diabetic patients with FU}

The treatment of CLI in diabetic patients with FUs is a topic of discussion in the last few years, and the majority of guidelines referred to general consensus or native experience. 
In case of FUs in diabetic patient with PAD, it is mandatory to evaluate the usefulness of revascularization and then the method of revascularization according to several parameters: the chance of healing, the foot aspect and its potential mechanical function after local surgical procedures, the arterial lesions and the patient's general conditions.

The chance of healing is related of foot perfusion, and this aspect is directly related to successful revascularization. In this context, $\mathrm{TcPO}_{2}$ may be helpful to detect the chance of healing and the indication to revascularize or not. Faglia et al have identified $\mathrm{TcPO}_{2}$ levels $<34 \mathrm{mmHg}$ as indication for revascularization due to the rate of $85 \%$ of amputation in the case of no revascularization; in patients with $\mathrm{TcPO}_{2}$ between 34 and $40 \mathrm{mmHg}$, the probability of amputation was $\sim 20 \%$ and the need of revascularization should be established according to physician's evaluation, while $\mathrm{TcPO}_{2}$ values of $>40 \mathrm{mmHg}$ revascularization should be considered in case of extended tissue loss, osteomyelitis treated by conservative approach or slow healing (ie, absence of signs of healing after 4-6 weeks of gold standard therapy). ${ }^{38}$

The residual foot function should be always considered in the limb salvage procedures. In case of severe impairment, primary amputation may be considered. However, also in this case, it is useful to evaluate the chance of revascularization to allow a more distal amputation (BTK), achieve the healing of amputation stump and improve the next rehabilitation.

In order to choose the best revascularization technique, it is mandatory to have an adequate knowledge of vascular tree (mainly the involvement of common iliac and femoral arteries) and to evaluate the distal runoff. Regardless of the revascularization approach, the procedure should ensure direct flow to dorsal pedal or plantar arch. ${ }^{39}$

Patient's general health needs to be considered, manly life expectancy and comorbidities. Bypass approach usually requires at least 2 years of life expectancy, while in case of life expectancy $<6$ months, there is no indication to any revascularization procedures. ${ }^{40}$ However, this is the general indication, but any situation should be analyzed case by case, considering the impaired quality of life related to peripheral ischemia.

According to comorbidities, the presence of dialysis complication should be considered in the evaluation of potential outcomes after limb salvage protocol. In fact, literature reports that between $22 \%$ and $44 \%$ of diabetic-dialyzed patients with CLI are candidates for primary amputation. They are very difficult to treat, and they show high shortterm $(3 \%-17 \%)$ and long-term mortality rate $(55 \%)$ that may influence the chance to revascularize these patients. ${ }^{41-43}$
In a recent paper, our group confirmed that diabetic patients with CLI and FUs on dialysis have reduced chances of healing and higher risk of major amputation and death if compared to non-dialyzed patients. ${ }^{44}$ We reported $65 \%$ of limb salvage, $21 \%$ of mortality and $14 \%$ of major amputation after endovascular revascularization in dialyzed patients during a mean follow-up of 15 months, while non-dialyzed patients had $78.2 \%$ of limb salvage, $10.8 \%$ of major amputation and $11 \%$ of death. In comparison to non-dialysis group, patients on dialysis had more steno-obstructions, higher risk of unsuccessful revascularization and needed more procedures to get limb salvage. However, it is hard to find a specific factor predictive of outcome in dialyzed subjects; therefore, we retain that all diabetic-dialyzed patients with ischemic FUs have to be considered as high-risk patients as a whole.

Our results obtained in diabetic-dialyzed patients are similar to those reported in literature in terms of limb salvage. ${ }^{45}$ However, it must be highlighted that in these studies, the outcomes are referred only to patients revascularized after a careful selection, while the outcomes reported in our study refer to unselected consecutive patients.

\section{Revascularization technique}

There is still an open debate on the first-line strategy between open surgery and endovascular revascularization in diabetic patients. PTA has shown good results in term of limb salvage, feasibility and complications, ${ }^{45-47}$ especially for infrainguinal lesions.

Even if bypass is characterized by a long-term patency, angioplasty can be performed in patients not suitable for bypass due to the presence of several comorbidities, reduced life expectancy, unavailability of veins, absence of landing zone for distal bypass and foot infection in the site of potential anastomosis. ${ }^{36,48-51}$ Angioplasty does not require general anesthesia and usually shows few contraindications in patients with active comorbidities. Furthermore, in fragile patients with impaired renal function and in case of complex procedure, angioplasty can be performed in various steps to reduce physical stress and the amount of contrast medium administered. However, it has been shown that through an adequate prophylaxis, the risk of contrast-induced nephropathy is very low also in patients with advanced renal failure. ${ }^{52}$

Angioplasty can also be easily repeated in case of restenosis or can be proposed after bypass failure. ${ }^{53-55}$

The choice of revascularization technique should be examined case by case according to vascular disease and local expertise. Obstruction of the common femoral artery and its bifurcation is usually suitable for surgical approach. In case 
of long occlusion of femoral-popliteal and infrapopliteal vessels, bypass is usually more effective and ensures long patency; however, there is a real consensus and this pattern of PAD may be treated by endovascular approach in centers with long experience with angioplasty. ${ }^{50,56-58}$ Atherectomy is considered as an alternative technique in the treatment of PAD to excise the atheroma by a rotating cutting blade. However, there is poor evidence to support atherectomy as an alternative to balloon angioplasty in maintaining primary patency. There was no evidence for superiority of atherectomy over angioplasty on any outcome..$^{59,60}$

\section{Current challenges and future perspectives \\ Unconventional techniques for treatment of complex BTK CLI}

The ipsilateral anterograde approach, allowing optimal pushability and trackability of guidewires and balloon catheters through infrapopliteal lesions, can ameliorate rates of complex BTK procedures compared to the contralateral common femoral approach.

Nevertheless, failure rates of conventional anterograde revascularization in intraluminal or subintimal manner for occlusive lesions still range from $10 \%$ to $40 \%$ in the BTK district, despite the use of innovative technologies and the development of dedicated devices. ${ }^{61-63}$

In the last few years, there has been a great evolution of endovascular strategies conceived to recanalize some complex patterns of CLI, thus enabling the treatment of a larger number of patients. Several alternative techniques have been proposed to increase the chance of success for tibioperoneal occlusions: pedal-plantar loop technique for the revascularization of foot arteries (Figure 1), trans-collateral angioplasty for chronic total occlusion of the tibial vessels (Figure 2) and combining intraluminal or subintimal recanalization with a double antegrade-retrograde approach puncturing either the pedal or the posterior tibial artery (PTa) performed in cases of femoropopliteal occlusions extending to the popliteal trifurcation or in order to preserve blood flow to the foot sustained by collaterals (Figure 3). ${ }^{64-67}$

Another unconventional revascularization technique has been described as a rescue strategy by Palena and Manzi ${ }^{68}$ who performed in cases of failure of anterograde approaches when tibial and pedal arteries are occluded or are not amenable for direct retrograde puncture, a retrograde direct puncture of the transmetatarsal arteries or the plantar arch with the encouraging result of $71 \%$ of amputation-free survival at 6 months of follow-up.
The increasingly widespread use of these alternative, albeit demanding, endovascular techniques has allowed a good rate of limb salvage in the treatment of complex occlusions in case of failed anterograde BTK revascularization attempts. In a recent study, our group reported a limb salvage rate of $83 \%$ at 6 months of follow-up using alternative techniques; furthermore, we had a reduction in major amputation ( $16 \%$ vs $39 \%$ ) in comparison to a previous study where conventional techniques were exclusively used. ${ }^{68}$

\section{Target revascularization}

Although Taylor and Palmer ${ }^{70}$ provided for the first time in 1987 with reconstructive plastic surgery purposes precious anatomical information about arteriovenous bundles called angiosomes, ${ }^{69}$ their clinical implications for limb salvage have been demonstrated only 10 years ago by Attinger et al who reported in a series of 52 distal bypasses higher unsuccessful wound healing rates $(38 \%)$ when ulcers were revascularized indirectly compared to lower unsuccessful wound healing rates $(9 \%)$ when ulcers were revascularized by their angiosomes. Since 2007, many prospective and retrospective studies ${ }^{71-76}$ have showed better outcomes for patients undergoing lower limb revascularization according to the angiosome theory; thus currently, the main aim of limb salvage procedures is to restore a direct straight-line inflow to the target wound area in agreement with these principles. According to the concept of wound-related artery and the abovementioned angiosome-directed revascularization, the usefulness of $\mathrm{TcPO}_{2}$ in the diagnosis of CLI in relation to wound site and corresponding angiosome has been also showed. Particularly, Izzo et $\mathrm{al}^{78}$ showed that in case of heel ulcer, $\mathrm{TcPO}_{2}$ recorded on the dorsum of the foot does not confirm the presence of CLI (not $<30 \mathrm{mmHg}$ ); a second oximetry recorded on the rearfoot may be useful to point out ischemia of the peroneal artery and/or of the posterior tibial artery.

\section{Venous arterialization}

Clinical effectiveness of BTK revascularization, performed either by traditional or unconventional techniques, is often poor in diabetic-dialyzed patients with CLI due to the severity of foot arteries disease. Improvement in peripheral perfusion is obtained approximately in only half of this peculiar subset of patients ${ }^{77}$ due to the more severe pattern of arterial disease, often characterized by long calcified occlusions that are extremely difficult to recanalize, especially in patients with heel ulcers and with involvement of posterior tibial artery. Moreover, a BTK amputation is mandatory in case of nonhealing heel ulcers, leading to worse prognosis. ${ }^{78}$ Long 


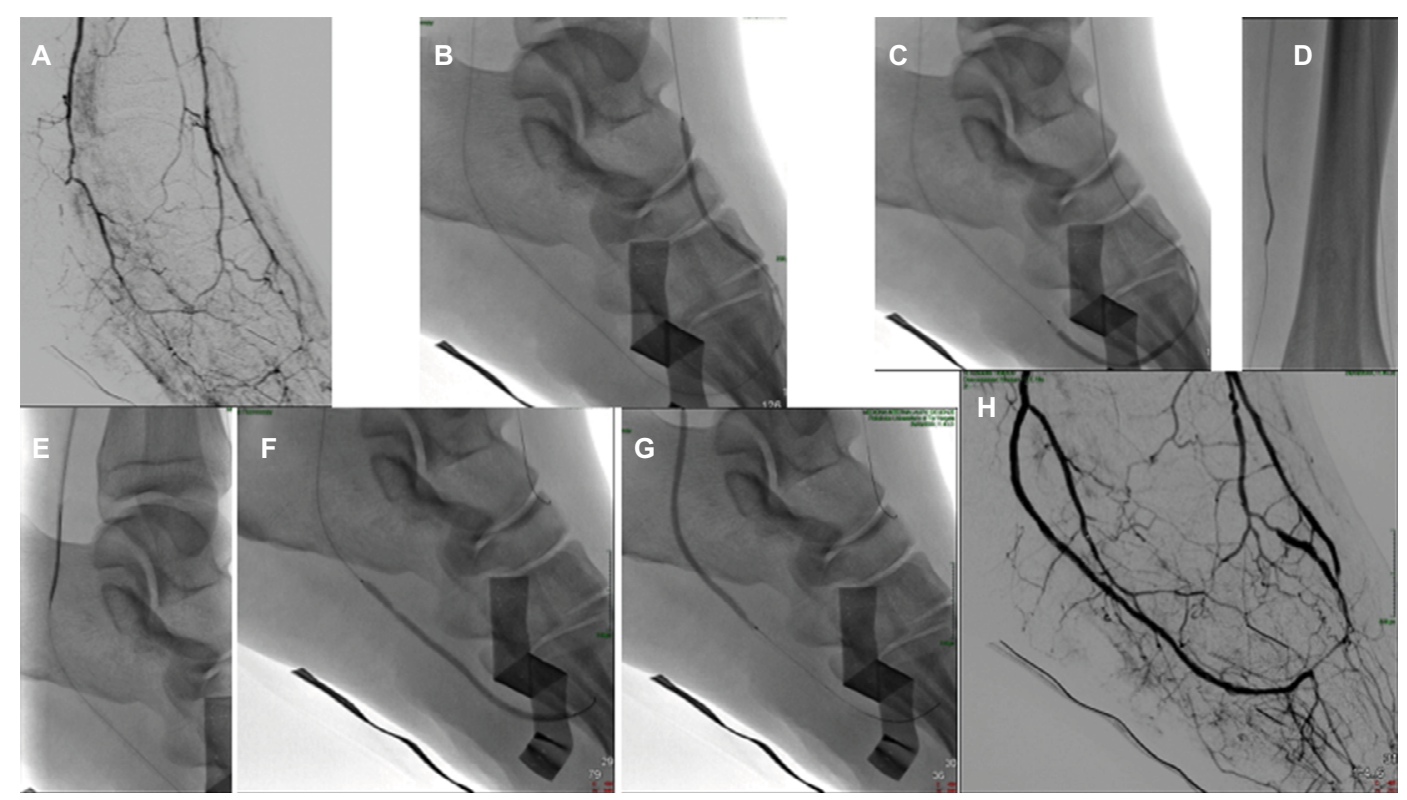

Figure I Pedal to plantar technique.

Notes: Preprocedural angiography (A). Multiple balloon dilatations performed in a pedal to plantar loop manner (B and $\mathbf{C})$. After the rendezvous in the PTa of the antegrade catheter and the retrograde guidewire advanced from the ATA ( $\mathbf{D}$ and $\mathbf{E}$ ), further balloon dilatations have been performed in an antegrade manner from the posterior tibial artery (F and $\mathbf{G})$. Final angiography $(\mathbf{H})$.

Abbreviation: PTa, posterior tibial artery.

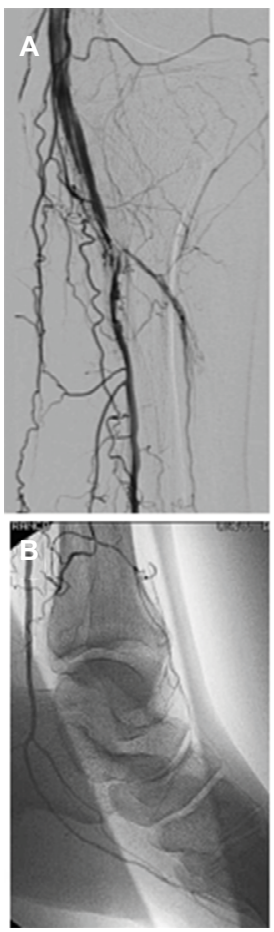

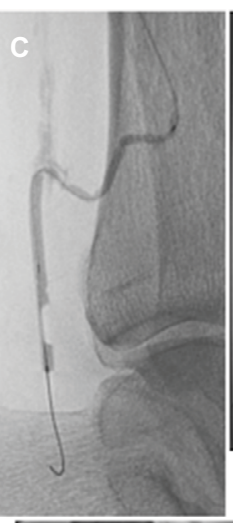
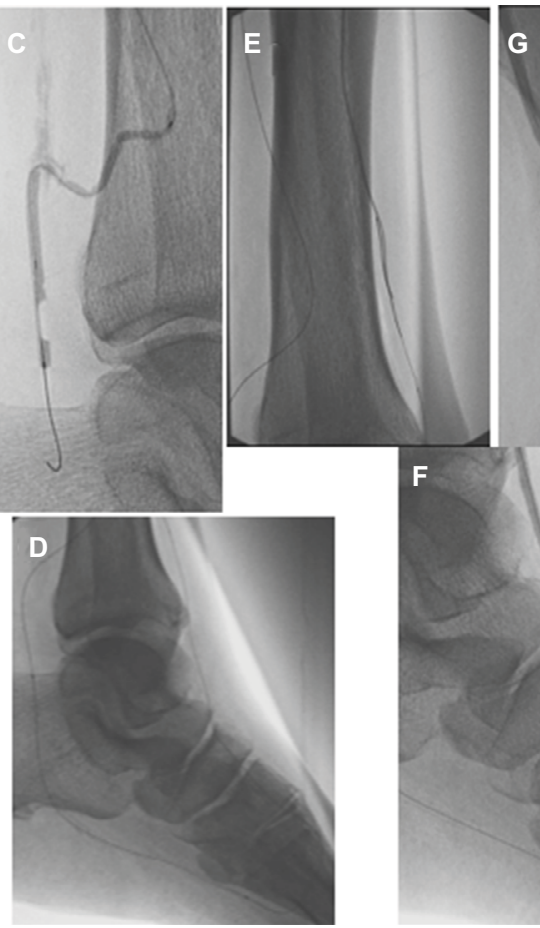
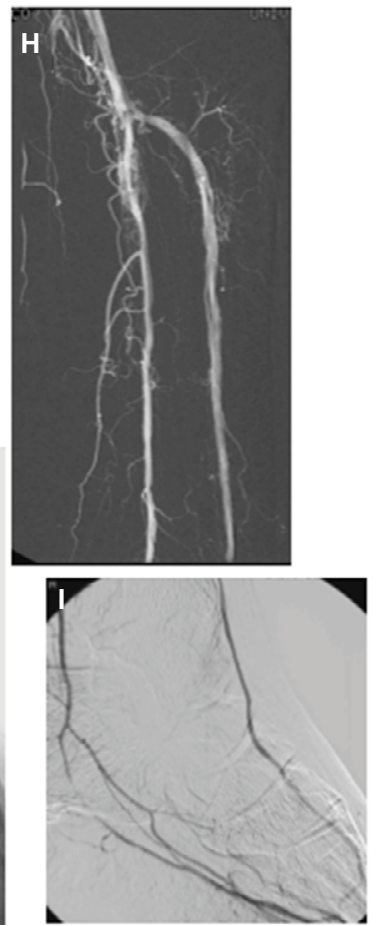

Figure 2 Trans-collateral technique.

Notes: Owing to the chronic occlusion of the ATA, in order to avoid damage to the anterior perforator branch of the peroneal artery, which sustained blood flow to the pedal artery (A and B), a retrograde recanalization of the plantar arch and the ATA through the lateral calcaneal branch of the peroneal artery was performed (C-E). After the rendezvous of the antegrade and retrograde guidewires in the ATA, multiple balloon dilatations were done in an antegrade manner (F and $\mathbf{G})$. Patency of the ATA lumen was reestablished at the final angiographic control $(\mathbf{H}$ and $\mathbf{I})$.

Abbreviation: ATA, anterior tibial artery. 


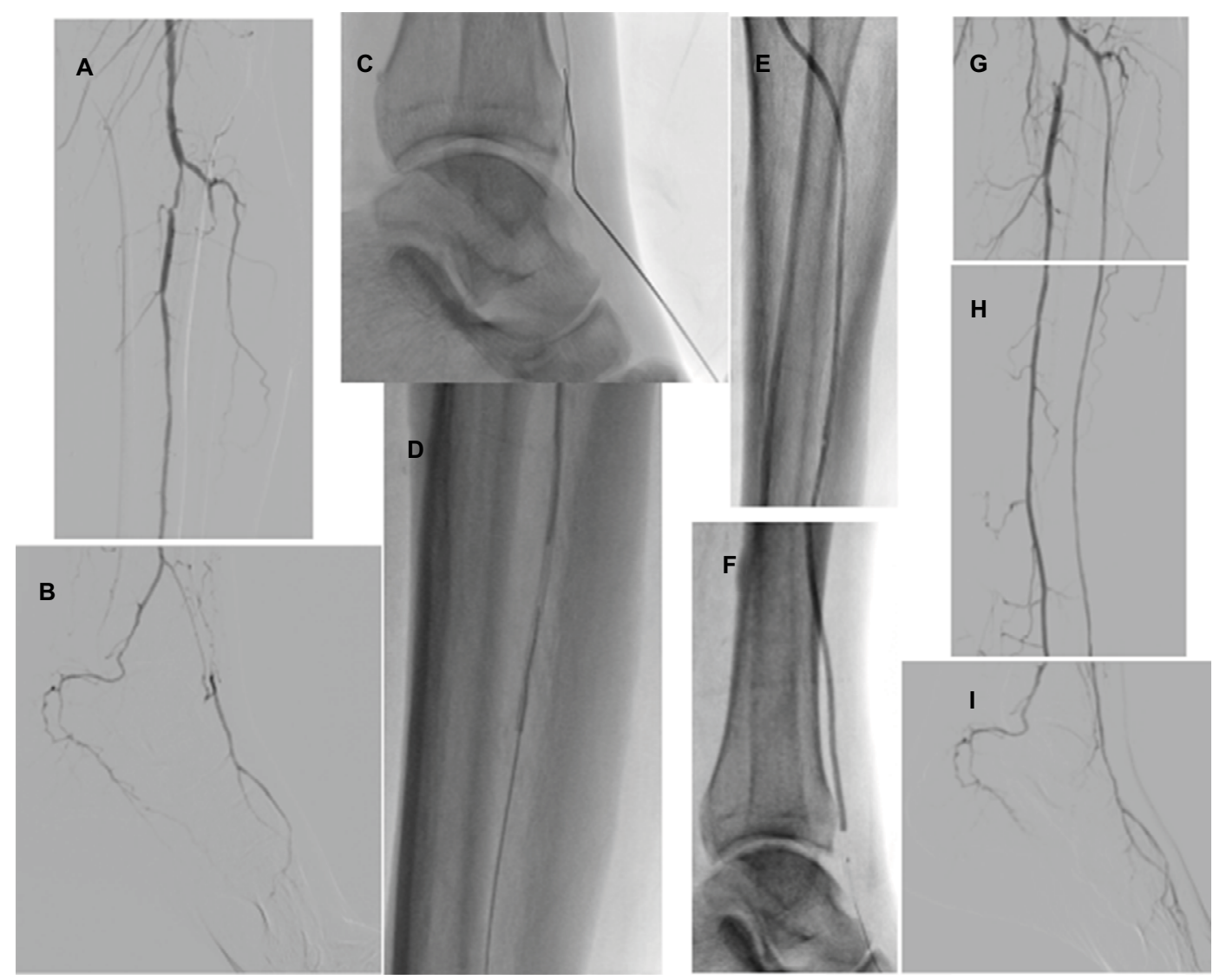

Figure 3 Double approach technique.

Notes: Preprocedural angiography showed occlusion of the ATA with patency of the pedal artery via the anterior perforator branch of the peroneal artery (A and B). In order to avoid the dissection of this precious collateral, the subintimal recanalization of the ATA was not extended beyond this level; therefore, a retrograde puncture of the plantar artery was performed (C). After the rendezvous (D) of the guidewires advanced in opposite directions, balloon dilatation (E and $\mathbf{F}$ ) from the antegrade approach was performed obtaining a direct straight flow to the forefoot (G-I).

Abbreviation: ATA, anterior tibial artery.

calcifications can hinder not only the intraluminal or subintimal progress of guidewires but also a potential intraluminal reentry from a subintimal space. In these cases, it might be very challenging to ensure an adequate flow in the wound area, especially in patients with poor or absent runoff.

A new technique has been recently proposed to cross the patchy calcifications of posterior tibial arteries and plantar arteries allowing the creation of an arteriovenous fistula with the surrounding plantar veins. ${ }^{79}$ The deep plantar venous arch runs from the proximal end of the first interosseous space to the base of the fifth metatarsal and accompanies the deep plantar arterial arch, which receives the deep metatarsal veins and surrounding muscular veins. In the deep plantar system, doubled veins have been constantly observed with the corresponding arteries. The vessels are surrounded by connective tissue, and this arrangement facilitates venous compression by the artery, serving as a localized pumping action. In this very recent paper, Gandini et al showed the potential role of this technique achieving direct blood flow to the lesion through the distal venous circulation by means of a completely percutaneous arterialization of the venous bed (Figure 4) in patients not treatable by conventional or alternative endovascular techniques due to long calcific occlusions of PTa and poor or absent runoff. In these case series, 33\% of patients underwent BTK amputation at 6 months after the procedure, while $66 \%$ had limb salvage. Although further investigations enrolling larger patient populations are needed, these data should be considered very encouraging in dialyzed patients affected by CLI in relation to the high risk of major amputation historically recorded in this complex subset of patients. Even if the earliest theories about the arterialization of the peripheral venous bed were developed more than one century ago, ${ }^{80}$ the mechanisms that may justify the benefits of venous arterialization for improving wound healing are still poorly understood, but reversed perfusion of arterioles through the arterial network of the foot and neovascularization stimulated by angiogenic factors seem to be the most likely explanations. ${ }^{81}$ 

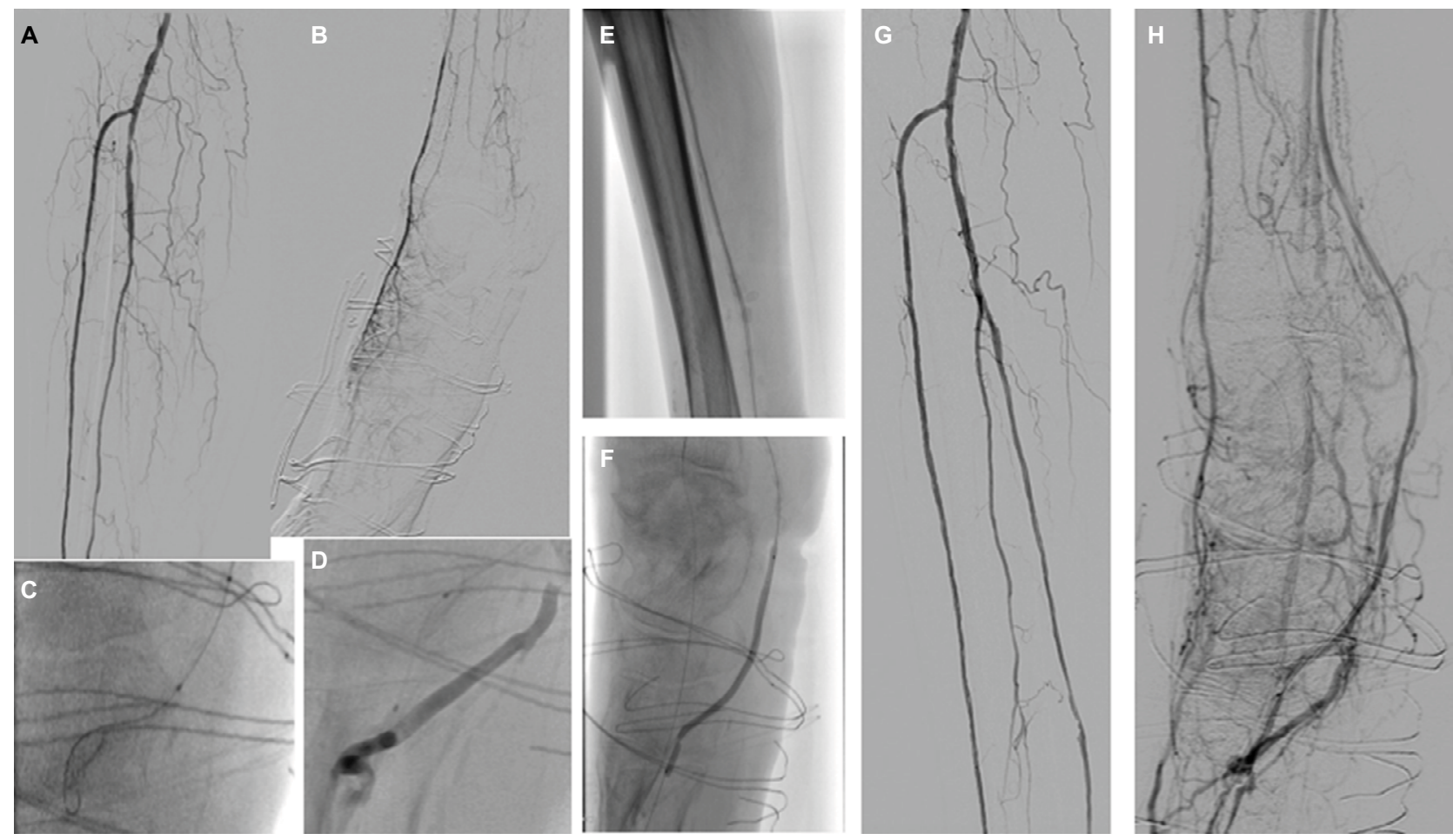

Figure 4 Distal venous arterialization.

Notes: Preprocedural angiography showed patency of the ATA and the peroneal artery with absence of the PTa, medial plantar artery and lateral plantar artery (A and B). After a failed intraluminal attempt, a subintimal recanalization of the PTa was performed, but a reentry in the true lumen of the medial plantar artery was not achieved. Therefore, an entry in the distal plantar vein was obtained $(\mathbf{C})$ and then confirmed by a gentle injection of a contrast medium through the balloon catheter (D). After balloon catheter dilatations of the arteriovenous fistula and the occluded arterial segment (E-F), postprocedural angiography showed patency of the PTa (G) and a good retrograde filling of the small distal venous channels toward the nonhealing wound area of the heel $(\mathbf{H})$.

Abbreviations: ATA, anterior tibial artery; PTa, posterior tibial artery.

\section{Gene and cell therapy}

There is a large amount of CLI not eligible for revascularization procedure due to several comorbidities, high operative risk, multiple failures of revascularization, high rate of restenosis or reocclusion after angioplasty and/or bypass. These patients are suitable for medical management, but the outcomes are poor in comparison to patients treated by successful revascularization, and in many circumstances, they are amputee due to the worsening of FU, infection and risk of sepsis, not tolerable pain. However, amputation can confer often a worse prognosis, being an independent predictor of death. ${ }^{82,83}$ In these non-revascularizable patients, currently, the new goal is to increase the local angiogenesis. Gene therapy offers a potential efficacious therapy with an acceptable rate of adverse events as documented in Phases I and II of different clinical trials. ${ }^{84-86}$ Various types of gene therapies have been studied (ie, fibroblast growth factor 1, vascular endothelial growth factor $[V E G F]$ and hepatocyte growth factor), of which the latter currently seems the most promising. ${ }^{87,88}$ Meta-analysis of randomized trials of gene therapy on $V E G F$ s did not show significant differences between active group and placebo. ${ }^{86}$ Otherwise, cell therapy seems to be effective in the treatment of CLI and reduction in major amputation is documented in diabetic and nondiabetic patients. ${ }^{86,89-91}$

Endothelial progenitor cells (EPCs) derived from bone marrow or peripheral blood are new emerging therapies to treat CLI in this subset of patients, promoting the regeneration of impaired endothelium and neoangiogenesis in ischemic tissues. $^{92}$

The effects of several types of cell therapy (eg, bone marrow-derived mononuclear cells, CD34+ bone marrow cells and mesenchymal stromal cells as well peripheral blood mononuclear cells) have been studied in CLI patients, and the rate of major amputation was significantly decreased after cell therapy in several trials, while other studies did not show any difference between treatment and placebo. ${ }^{93,94}$ This discrepancy between the preclinical and the clinical results of cell therapy in CLI may be explained by the potential role of disease-mediated stem cell dysfunction, which may limit the effects of these autologous cell therapies. However, mesenchymal stem cells appear less sensitive to this 
disease-mediated dysfunction and can be considered as a promising target for next future cell therapy in CLI patients. ${ }^{95}$

Different studies about autologous cell therapy in CLI subjects included diabetic patients in whom the healing process may be influenced by different parameters such as hyperglycemia and peripheral neuropathy that can interfere with the outcomes of clinical trials.

In CLI patients, angiogenesis is reduced, mainly in diabetic patients with hyperglycemia, due to the reduction in hypoxia-dependent protection of hypoxia-inducible factor 1 -alpha against proteasomal degradation. ${ }^{96}$ Furthermore, the increased plasma levels of nitric oxide inhibit angiogenesis and proangiogenic growth factors. Hyperglycemia can also inhibit hypoxia-induced expression of $V E G F \mathrm{~s} .{ }^{97}$ The mechanism of therapeutic angiogenesis is not already completely clear; the arterial neoformation is usually reduced by local inflammation that affects microcirculation, and the neoformation of collateral vessels is not allowed. Cell therapy allows therapeutic angiogenesis also in these circumstances, promoting the formation of new vessels from preexisting smaller vessels that can take days or weeks to develop. This principle appears to be a long and complex biologic process related to the release of hypoxia-inducible factor 1-alpha and $V E G F \mathrm{~s}$ in the environment of ischemic tissues. ${ }^{98-100}$

Although both gene- and cell-based therapies in CLI seem to be encouraging in the potential treatment in a subset of patients, all of these studies need more double-blinded control studies and the evaluation of longer outcomes in terms of wound healing, amputation, safety and quality of life to reinforce the initial promising results of these novel therapies.

\section{Author contributions}

All the authors give a substantial contribution to conception and design. They revised the manuscript critically for intellectual content and approved the final version to be published.

\section{Disclosure}

The authors report no conflicts of interest in this work.

\section{References}

1. Murabito JM, Evans JC, Nieto K, Larson MG, Levy D, Wilson PW. Prevalence and clinical correlates of peripheral arterial disease in the Framingham Offspring Study. Am Heart J. 2002;143(6):961-965.

2. Adam DJ, Beard JD, Cleveland T, et al; BASIL trial participants. Bypass versus angioplasty in severe ischaemia of the leg (BASIL): multicentre, randomised controlled trial. Lancet. 2005;366(9501):1925-1934.

3. Stoyioglou A, Jaff MR. Medical treatment of peripheral arterial disease: a comprehensive review. JVasc Interv Radiol. 2004;15(11):1197-1207.

4. Steg PG, Bhatt DL, Wilson PW, et al; REACH Registry Investigators. One-year cardiovascular event rates in outpatients with atherothrombosis. JAMA. 2007;297(11):1197-1206.
5. Caro J, Migliaccio-Walle K, Ishak KJ, Proskorovsky I. The morbidity and mortality following a diagnosis of peripheral arterial disease: long-term follow-up of a large database. BMC Cardiovasc Disord. 2005;5:14.

6. Abu Dabrh AM, Steffen MW, Undavalli C, et al. The natural history of untreated severe or critical limb ischemia. J Vasc Surg. 2015;62(6):1642-1651.

7. Norgren L, Hiatt WR, Dormandy JA, Nehler MR, Harris KA, Fowkes FG. Intersociety consensus for the management of peripheral arterial disease (TASC II). J Vasc Surg. 2007;45(suppl S):S5-S67.

8. Strandness DJ, Sumner D. Hemodynamics for Surgeons. New York: Grune \& Stratton; 1975:278-281.

9. Criqui MH, Fronek A, Klauber MR, Barret-Connor E, Gabriel S. The sensitivity, specificity, and predictive value of traditional clinical evaluation of peripheral arterial disease: results from noninvasive testing in a defined population. Circulation. 1985;71(3):516-522.

10. Orchard J, Strandness DE Jr. Assessment of peripheral vascular disease in diabetes. Report and recommendations of an international workshop sponsored by the American Heart association and the American Diabetes Association. Diabetes Care. 1993;16:1119-1209.

11. Young MJ, Adams JE, Anderson GF, Boulton AJ, Cavanagh PR. Medial arterial calcification in the feet of diabetic patients and matched nondiabetic control subjects. Diabetologia. 1993;36(7):615-621.

12. Park SC, Choi CY, Ha YI, Yang HE. Utility of toe-brachial index for diagnosis of peripheral artery disease. Arch Plast Surg. 2012;39(3):227-231.

13. Ballad JL, Eke CC, Bunt TJ, Killen JD. A prospective evaluation of transcutaneous oxygen measurements in the management of diabetic foot problems. J Vasc Surg. 1995;22(4):485-490.

14. Bradbury AW, Adam DJ. Diagnosis of peripheral arterial disease of the lower limb. BMJ. 2007;334(7606):1229-1230.

15. Visser K, Hunink MG. Peripheral arterial disease: gadoliniumenhanced MR angiography versus color color-guided duplex: a metaanalysis. Radiology. 2000;216(1):67-77.

16. Hingorani A, Ascher E, Marks N. Preprocedural imaging: new options to reduce need for contrast angiography. Semin Vasc Surg. 2007;20(1):15-28.

17. Prince MR, Zhang H, Morris M, et al. Incidence of nephrogenic systemic fibrosis at two large medical centers. Radiology. 2008;248(3): 807-816.

18. Rydahl C, Thomsen HS, Marckmann P. High prevalence of nephrogenic systemic fibrosis in chronic renal failure patients exposed to gadodiamide, a gadolinium-containing magnetic resonance contrast agent. Invest Radiol. 2008;43(2):141-144.

19. Wertman R, Altun E, Martin DR, et al. Risk of nephrogenic systemic fibrosis: evaluation of gadolinium chelate contrast agents at four American Universities. Radiology. 2008;248(3):799-806.

20. Met R, Bipat S, Legemate DA, Reekers JA, Koelemay MJ. Diagnostic performance of computed tomography angiography in peripheral arterial disease: a systematic review and meta-analysis. JAMA. 2009;301(4):415-424.

21. Stegemann E, Tegtmeier C, Bimpong-Buta NY, et al. Carbondioxideaided angiography decreases contrast volume and preserves kidney function in peripheral vascular interventions. Angiology. 2016;67(9):875-881.

22. Willigendael EM, Teijink JA, Bartelink ML, Peters RJ, Buller HR, Prins MH. Smoking and the patency of lower extremity bypass grafts: a meta-analysis. J Vasc Surg. 2005;42(1):67-74.

23. Armstrong EJ, Wu J, Singh GD, et al. Smoking cessation is associated with decreased mortality and improved amputation-free survival among patients with symptomatic peripheral artery disease. $J$ Vasc Surg. 2014;60(6):1565-1571.

24. Heart Protection Study Collaborative Group. MRC/BHF Heart Protection Study of cholesterol lowering with simvastatin in 20,536 high-risk individuals: a randomised placebo-controlled trial. Lancet. 2002;360(9326):7-22. 
25. Hirsch AT, Haskal ZJ, Hertzer NR, et al. ACC/AHA 2005 guidelines for the management of patients with peripheral arterial disease (lower extremity, renal, mesenteric, and abdominal aortic): executive summary a collaborative report from the American Association for Vascular Surgery/Society for Vascular Surgery, Society for Cardiovascular Angiography and Interventions, Society for Vascular Medicine and Biology, Society of Interventional Radiology, and the ACC/AHA task force on practice guidelines (writing committee to develop guidelines for the management of patients with peripheral arterial disease) endorsed by the American Association of Cardiovascular and Pulmonary Rehabilitation; National Heart, Lung, and Blood Institute; Society for Vascular Nursing; Trans-Atlantic Inter-Society Consensus; and Vascular Disease Foundation. J Am Coll Cardiol. 2006;47:1239-1312.

26. Rubins HB, Robins SJ, Collins D, et al. Gemfibrozil for the secondary prevention of coronary heart disease in men with low levels of high-density lipoprotein cholesterol. Veterans affairs high-density lipoprotein cholesterol intervention trial study group. $N$ Engl $J$ Med. 1999;341(6):410-418.

27. ESH/ESC. 2003 European Society of Hypertension-European Society of Cardiology guidelines for the management of arterial hypertension. J Hypertens. 2003;21(6):1011-1053.

28. XXXX. Intensive blood-glucose control with sulphonylureas or insulin compared with conventional treatment and risk of complications in patients with type 2 diabetes (UKPDS 33). UK Prospective Diabetes Study (UKPDS) group. Lancet. 1998;352(9131): 837-853.

29. Dormandy JA, Charbonnel B, Eckland DJ, et al. PROactive Investigators. Secondary prevention of macrovascular events in patients with type 2 diabetes in the PROactive Study (PROspective pioglitAzone Clinical Trial In macroVascular events): a randomised controlled trial. Lancet. 2005;366(9493):1279-1289.

30. Giurato L, Vainieri E, Meloni M, et al. Limb salvage in patients with diabetes is not a temporary solution but a life-changing procedure. Diabetes Care. 2015;38(10):e156-e157.

31. Uccioli L, Gandini R, Giurato L, et al. Long-term outcomes of diabetic patients with critical limb ischemia followed in a tertiary referral diabetic foot clinic. Diabetes Care. 2010;33(5):977-982.

32. Owen RJ, Hiremath S, Myers A, Fraser-Hill M, Barrett BJ. Canadian association of radiologists consensus guidelines for the prevention of contrast-induced nephropathy: update 2012. Can Assoc Radiol J. 2014;65(2):96-105.

33. Antithrombotic Trialists' Collaboration. Collaborative meta-analysis of randomised trials of antiplatelet therapy for prevention of death, myocardial infarction, and stroke in high risk patients. $\mathrm{Br}$ Med $\mathrm{J}$. 2002;324(7329):71-86.

34. Aiello A, Anichini R, Brocco E, et al. Treatment of peripheral arterial disease in diabetes: a consensus of the Italian Societies of Diabetes (SID, AMD), Radiology (SIRM) and Vascular Endovascular Surgery (SICVE). Nutr Metab Cardiovasc Dis. 2014;24(4):355-369.

35. Bradbury AW, Ruckley CV, Fowkes FGR, et al. Bypass versus angioplasty in severe ischaemia of the leg (BASIL): multicentre, randomised controlled trial. Lancet. 2002;366(2005):1925-1934.

36. Romiti M, Albers M, Brochado-Neto FC, Durazzo AE, Pereira CA, De LN. Meta-analysis of infrapopliteal angioplasty for chronic critical limb ischemia. J Vasc Surg. 2008;47(5):975-981.

37. Albers M, Romiti M, Brochado-Neto FC, Pereira CA. Meta-analysis of alternate autologous vein bypass grafts to infrapopliteal arteries. J Vasc Surg. 2005;42(3):449-455.

38. Faglia E, Clerici G, Caminiti M, Quarantiello A, Curci V, Morabito A. Predictive values recorded of transcutaneous oxygen tension for above-the-ankle amputation in diabetic patients with critical limb ischemia. Eur J Vasc Endovasc Surg. 2007;33(6):731-736.

39. Söderström MI, Arvela EM, Korhonen M, et al. Infrapopliteal percutaneous transluminal angioplasty versus bypass surgery as first-line strategies in critical leg ischemia: a propensity score analysis. Ann Surg. 2010;252(5):765-773.
40. Schaper NC, Andros G, Apelqvist J, et al. Diagnosis and treatment of peripheral arterial disease in diabetic patients with a foot ulcer. A progress report of the International Working Group on the Diabetic Foot. Diabetes Metab Res Rev. 2012;28(suppl 1):236-237.

41. Hinchliffe RJ, Andros G, Apelqvist J, et al. A systematic review of the effectiveness of revascularization of the ulcerated foot in patients with diabetes and peripheral arterial disease. Diabetes Metab Res Rev. 2012;28(suppl 1):179-217.

42. Johnson BL, Glickman MH, Bandyk DF, Esses GE. Failure of foot salvage in patients with end-stage renal disease after surgical revascularization. J Vasc Surg. 1995;22(3):280-285.

43. Venermo M, Biancari F, Arvela E, et al. The role of chronic kidney disease as a predictor of outcome after revascularisation of the ulcerated diabetic foot. Diabetologia. 2011;54(12):2971-2977.

44. Meloni M, Giurato L, Izzo V, et al. Long term outcomes of diabetic haemodialysis patients with critical limb ischemia and foot ulcer. Diabetes Res Clin Pract. 2016;116:117-122.

45. Ferraresi R, Centola M, Ferlini M, et al. Long-term outcomes after angioplasty of isolated, below-the-knee arteries in diabetic patients with critical limb ischaemia. Eur J Vasc Endovasc Surg. 2009;37(3):336-342.

46. Giurato L, Gandini R, Meloni M, et al. Percutaneous angioplasty in diabetic patients with critical limb ischemia and chronic kidney disease. Open J Endocr Metab Dis. 2013;3(3):208-212.

47. Caravaggi C, De Giglio R, Pritelli C, et al. Extensive use of peripheral angioplasty, particularly infrapopliteal, in the treatment of ischaemic diabetic foot ulcers: clinical results of a multicentric study of 221 consecutive diabetic subjects. $J$ Intern Med. 2002;252(3): 225-232.

48. Graziani L, Piaggesi A. Indications and clinical outcomes for below knee endovascular therapy: review article. Catheter Cardiovasc Interv. 2010;75(3):433-443.

49. Faglia E, Clerici G, Clerissi J, et al. Long term prognosis of diabetic patients with critical limb ischemia: a population based cohort study. Diabetes Care. 2009;32(5):822-827.

50. Weis-Müller BT, Römmler V, Lippelt I, et al. Critical chronic peripheral arterial disease: does outcome justify crural or pedal bypass surgery in patients with advanced age or with comorbidities? Ann Vasc Surg. 2011;25(6):783-795.

51. Werneck CC, Lindsay Tibial TF. angioplasty for limb salvage in highrisk patients and cost analysis. Ann Vasc Surg. 2009;23(5):554-559.

52. Pomposelli FB, Kansal N, Hamdan AD, et al. A decade of experience with dorsalis pedis artery by-pass: analysis of outcome in more than 1000 cases. J Vasc Surg. 2003;37(2):307-315.

53. Pomposelli FB Jr, Marcaccio EJ, Gibbons GW, et al. Dorsalis pedis arterial bypass: durable limb salvage for foot ischemia in patients with diabetes mellitus. J Vasc Surg. 1995;21(3):375-384.

54. Meloni M, Izzo V, Giurato L, et al. Risk of contrast induced nephropathy in diabetic patients affected by critical limb ischemia and diabetic foot ulcers treated by percutaneous transluminal angioplasty of lower limbs. Diabetes Metab Res Rev. 2017;33(3).

55. Faglia E, Clerici G, Clerissi J, et al. Angioplasty for diabetic patients with failing bypass graft or residual critical ischemia after bypass graft. Eur J Vasc Endovasc Surg. 2008;36(3):331-338.

56. Dick F, Diehm N, Galimanis A, Husmann M, Schmidli J, Baumgartner I. Surgical or endovascular revascularization in patients with critical limb ischemia: influence of diabetes mellitus on clinical outcome. J Vasc Surg. 2007;45(4):751-761.

57. Gandini R, Chiappa R, Di Primio M, et al. Recanalization of the native artery in patients with bypass failure. Cardiovasc Intervent Radiol. 2009;32(6):1146-1153.

58. Diehm N, Shang A, Silvestro A, et al. Association of cardiovascular risk factors with pattern of lower limb atherosclerosis in 2659 patients undergoing angioplasty. Eur JVasc Endovasc Surg. 2006;31(1):59-63.

59. Ambler GK, Radwan R, Hayes PD, Twine CP. Atherectomy for peripheral arterial disease. Cochrane Database Syst Rev. 2014;3:CD006680. 
60. Schmidt A, Ulrich M, Winkler B, et al. Angiographic patency and clinical outcome after balloon-angioplasty for extensive infrapopliteal arterial disease. Catheter Cardiovasc Interv. 2010;76(7):1047-1054.

61. Gargiulo M, Giovanetti F, Bianchini Massoni C, et al. Bypass to the ankle and foot in the era of endovascular therapy of tibial disease. Results and factors influencing the outcome. J Cardiovasc Surg (Torino). 2012;55(3):367-374.

62. Bosiers M, Hart JP, Deloose K, Verbist J, Peeters P. Endovascular therapy as the primary approach for limb salvage in patients with critical limb ischemia: experience with 443 infrapopliteal procedures. Vascular. 2006;14(2):63-69.

63. Papavassiliou VG, Walker SR, Bolia A, Fishwick G, London N. Techniques for the endovascular management of complications following lower limb percutaneous transluminal angioplasty. Eur JVasc Endovasc Surg. 2003;25(2):125-130.

64. Soder HK, Manninen HI, Jaakola P, et al. Prospective trial of infrapopliteal artery balloon angioplasty for critical limb ischemia: angiographic and clinical results. J Vasc Interv Radiol. 2000;11(8):1021-1031.

65. Gandini R, Pipitone V, Stefanini M, et al. The "Safari" technique to perform difficult subintimal infragenicular vessels. Cardiovasc Intervent Radiol. 2007;30(3):469-473.

66. Manzi M, Fusaro M, Ceccacci T, et al. Clinical results of belowthe knee intervention using pedal-plantar loop technique for the revascularization of foot arteries. J Cardiovasc Surg (Torino) 2009;50(3):331-337.

67. Fusaro M, Agostoni P, Biondi-Zoccai G. "Trans-collateral" angioplasty for a challenging chronic total occlusion of the tibial vessels: a novel approach to percutaneous revascularization in critical lower limb ischemia. Catheter Cardiovasc Interv. 2008;71(2):268-272.

68. Palena LM, Manzi M. Extreme below-the-knee interventions: retrograde transmetatarsal or transplantar arch access for foot salvage in challenging cases of critical limb ischemia. J Endovasc Ther. 2012;19(6):805-811.

69. Gandini R, Uccioli L, Spinelli A, et al. Alternative techniques for treatment of complex below-the knee arterial occlusions in diabetic patients with critical limb ischemia. Cardiovasc Intervent Radiol. 2013;36(1):75-83.

70. Taylor GI, Palmer JH. The vascular territories (angiosomes) of the body: experimental study and clinical applications. Br J Plast Surg. 1987;40(2):113-141.

71. Attinger CE, Evans KK, Bulan E, Blume P, Cooper P. Angiosomes of the foot and ankle and clinical implications for limb salvage: reconstruction, incisions, and revascularization. Plast Reconstr Surg. 2006;117(suppl 7):261S-293S.

72. Fossaceca R, Guzzardi G, Cerini P, et al. Endovascular treatment of diabetic foot in a selected population of patients with below-the-knee disease: is the angiosome model effective? Cardiovasc Intervent Radiol. 2013;36(3):637-644.

73. Alexandrescu V, Vincent G, Azdad K, et al. A reliable approach to diabetic neuroischemic foot wounds: below-the-knee angiosomeoriented angioplasty. J Endovasc Ther. 2011;18(3):376-387.

74. Iida O, Soga Y, Hirano K, et al. Long-term results of direct and indirect endovascular revascularization based on the angiosome concept in patients with critical limb ischemia presenting with isolated belowthe-knee lesions. J Vasc Surg. 2012;55(2):363-370.e5.

75. Söderström M, Albäck A, Biancari F, Lappalainen K, Lepäntalo M, Venermo M. Angiosome-targeted infrapopliteal endovascular revascularization for treatment of diabetic foot ulcers. J Vasc Surg. 2013;57(2):427-435.

76. Lejay A, Georg Y, Tartaglia E, et al. Long-term outcomes of direct and indirect below-the-knee open revascularization based on the angiosome concept in diabetic patients with critical limb ischemia. Ann Vasc Surg. 2013;28(4):983-989.

77. Izzo V, Meloni M, Fabiano S, et al. Transcutaneous oximetry is a useful tool to highlight ischemia of the heel. Cardiovasc Intervent Radiol. 2017;40(1):120-124.
78. Brosi P, Baumgartner I, Silvestro A, et al. Below-the-knee angioplasty in patients with end-stage renal disease. $J$ Endovasc Ther. 2005;12(6):704-713.

79. Edmonds ME, Blundell MP, Morris ME, Thomas EM, Cotton LT, Watkins PJ. Improved survival of the diabetic foot: the role of a specialized foot clinic. $Q J$ Med. 1986;60(232):763-771.

80. Gandini R, Merolla S, Scaggiante J, et al. Endovascular distal plantar venous arterialization in dialyzed patients with critical limb ischemia and posterior tibial artery occlusion: a technical note of a new frontier of Limb Salvage in a challenging subset of patients. J Endovasc Ther. 2018;25(1): 127-132.

81. Francois-Franck M. Note a propos de la communication de M Raimond Petit sur la susture arterio-veneuse. Compt Rend Hebd Soc Biol. 1896;48:150

82. Matolo NM, Cohen SW, Wolfman EF. Use of an arteriovenous fistula for treatment of the severely ischemic extremity: experimental evaluation. Ann Surg. 1976;184(5):622-625.

83. Uccioli L, Giurato L, Meloni M, et al. Comment on Hoffstad et al. diabetes, lower-extremity amputation, and death. Diabetes Care 2015;38:1852-1857. Diabetes Care. 2016;39(1):e7.

84. Hoffstad O, Mitra N, Walsh J, Margolis DJ. Diabetes, lower-extremity amputation, and death. Diabetes Care. 2015;38(10):1852-1857.

85. Rajagopalan S, Mohler ER, Lederman RJ, et al. Regional angiogenesis with vascular endothelial growth factor in peripheral arterial disease $-\mathrm{a}$ phase II randomized, double-blind, controlled study of adenoviral delivery of vascular endothelial growth factor 121 in patients with disabling intermittent claudication. Circulation. 2003;108(16):1933-1938.

86. Powell RJ, Simons M, Mendelsohn FO, et al. Results of a double-blind, placebo-controlled study to assess the safety of intramuscular injection of hepatocyte growth factor plasmid to improve limb perfusion in patients with critical limb ischemia. Circulation. 2008;118(1):58-65.

87. Nikol S, Baumgartner I, Van Belle E, et al. Therapeutic angiogenesis with intramuscular NV1FGF improves amputation-free survival in patients with critical limb ischemia. Mol Ther. 2008;16(5):972-978.

88. Ko SH, Bandyk DF. Therapeutic angiogenesis for critical limb ischemia. Semin Vasc Surg. 2014;27(1):23-31.

89. Fadini GP, Agostini C, Avogaro A. Autologous stem cell therapy for peripheral arterial disease meta-analysis and systematic review of the literature. Atherosclerosis. 2010;209(1):10-17.

90. Lawall H, Bramlage P, Amann B. Stem cell and progenitor cell therapy in peripheral artery disease. A critical appraisal. Thromb Haemost. 2010;103(4):696-709.

91. Liu Y, Xu Y, Fang F, Zhang J, Guo L, Weng Z. Therapeutic efficacy of stem cell-based therapy in peripheral arterial disease: a meta-analysis. PLoS One. 2015;10(4):e0125032.

92. Wang ZX, Li D, Cao JX, et al. Efficacy of autologous bone marrow mononuclear cell therapy in patients with peripheral arterial disease. J Atheroscler Thromb. 2014;21(11):1183-1196.

93. Tongers J, Roncalli JG, Losordo DW. Therapeutic angiogenesis for critical limb ischemia - microvascular therapies coming of age. $\mathrm{Cir}$ culation. 2008;118(1):9-16.

94. Peeters Weem SM, Teraa M, de Borst GJ, Verhaar MC, Moll FL. Bone marrow derived cell therapy in critical limb ischemia: a meta-analysis of randomized placebo controlled trials. Eur J Vasc Endovasc Surg. 2015;50(6):775-783.

95. Teraa M, Sprengers RW, van der GraafY, Peters CE, Moll FL, Verhaar MC. Autologous bone marrow-derived cell therapy in patients with critical limb ischemia: a meta-analysis of randomized controlled clinical trials. Ann Surg. 2013;258(6):922-929.

96. Gremmels H, Teraa M, Quax PH, den Ouden K, Fledderus JO, Verhaar MC. Neovascularization capacity of mesenchymal stromal cells from critical limb ischemia patients is equivalent to healthy controls. $\mathrm{Mol}$ Ther. 2014;22(11):1960-1970.

97. Catrina SB, Okamoto K, Pereira T, Brismar K, Poellinger L. Hyperglycemia regulates hypoxia-inducible factor 1-alpha protein stability and function. Diabetes. 2004;53(12):3226-3232. 
98. Uccioli L, Izzo V, Meloni M, Vainieri E, Ruotolo V, Giurato L. Nonhealing foot ulcers in diabetic patients: general and local interfering conditions and management options with advanced wound dressings. J Wound Care. 2015;24(4 suppl):35-42.

99. Buschmann I, Schaper W. Arteriogenesis versus angiogenesis: two mechanisms of vessels growth. News Physiol Sci. 1999;14: 121-125.
100. Halstead AE, Vaughan RT. Arteriovenous anastomosis in the treatment of gangrene of the extremities. Surg Gynecol Obstet. 1912;14:1.

\section{Publish your work in this journal}

Vascular Health and Risk Management is an international, peerreviewed journal of therapeutics and risk management, focusing on concise rapid reporting of clinical studies on the processes involved in the maintenance of vascular health; the monitoring, prevention and treatment of vascular disease and its sequelae; and the involvement of metabolic disorders, particularly diabetes. This journal is indexed on PubMed Central and MedLine. The manuscript management system is completely online and includes a very quick and fair peer-review system, which is all easy to use. Visit http://www.dovepress.com/ testimonials.php to read real quotes from published authors. 